\title{
Perancangan Alarm Anti Maling pada Kendaraan Bermotor Dalam Posisi Parkir Menggunakan Sensor PIR ( Passive Infrared Receiver ) Dan Sensor Getar Berbasis Arduino uno R3
}

\author{
Jhonny hendra cipta Pangaribuan, Indra Gunawan, Heru Satria T, Sumarno, Ika okta kirana \\ Program Studi Teknik Informatika \\ AMIK dan STIKOM Tunas Bangsa Pematangsiantar \\ jhonnyhendra10@gmail.com
}

\begin{abstract}
Abstrak
Masyarakat merasa keamanan saat ini tidaklah kondusif, banyak perampokan dan penodongan terhadap kendaraan bermotor, khususnya di area parkir dan mengakibatkan kerugian materi yang bagi kelas masyarakat tertentu dinilai besar. Semakin meningkatnya kebutuhan masyarakat dalam penggunaan perangkat keamanan pada kendaraan bermotor mereka, terutama untuk sekarang ini belum banyak kendaraan yang di lengkapi sensor keamanan dari pabrikan pembuat kendaraan bermotor. Hal ini mendorong penulis untuk merancang perangkat pengaman pada kendaraan bermotor. Sistem pengaman ini menggunakan mikrokontroler Arduino Uno r3 yang dihubungkan dengan sensor PIR dan sensor SW-420 vibration sensor. Sensor PIR akan mendeteksi adanya pergerakan di sekitar kendaraan bermotor yang menyebabkan adanya perubahan tegangan. Perubahan tegangan dari sensor kemudian akan dijadikan sebagai data input oleh mikro kontroler dan diproses sehingga membuat LCD menyala serta buzzer/alarm berbunyi. Sistem pengaman ini mampu mendeteksi keberadaan manusia yang masuk dalam cakupan/coverage area sensor, maka suhu tubuh yang di pancarkan manusia akan di deteksi dan selanjutnya sensor akan aktif. Sedangkan sensor SW-420 akan mendeteksi getaran yang di timbulkan dari sentuhan atau getaran dari objek(manusia).
\end{abstract}

Kata Kunci : Mikrokontroler, sensor PIR, buzzer, sensor SW-420 vibration.

\begin{abstract}
The community feels that security at this time is not conducive. Many robberies and robbery of motorized vehicles, especially in the parking area, resulting in material losses, which are considered large for certain classes of society. Increasing needs of the community in the use of security devices on their motor vehicles, especially, for now, not many cars are equipped with safety sensors from manufacturers of motor vehicle manufacturers. This prompted the authors to design safety devices on motor vehicles. This security system uses an ARDUINO UNO R3 microcontroller connected to the PIR sensor and SW-420 vibration sensor. PIR sensor will detect any movement around the motorized vehicle, which causes a change in voltage. The sensor's voltage will then be used as input data by the microcontroller and processed so that the LCD will turn on, and the buzzer/alarm will sound. This safety system can detect humans who fall within the sensor coverage area, then the body temperature emitted by humans will be seen, and the sensor will then be active. In comparison, the SW-420 sensor will detect vibrations caused by touch or vibrations from objects (humans).
\end{abstract}

Keywords: Microcontroller, PIR sensor, buzzer, $S W-420$ vibration sensor. 


\section{PENDAHULUAN}

Aspek keamanan sangat dibutuhkan dalam berbagai sektor kehidupan saaat ini, faktor privasi juga turut mempengaruhi akan pentingnya suatu sistem keamanan. Banyak sarana yang dirancang secara otomatis untuk membantu kegiatan manusia dalam mengatur keamanan lingkungan ataupun ruangan yang memerlukan tingkat pengamanan yang lebih ketat. Khususnya pada kendaran bermotor bila ingin terhindar dari kriminalitas seperti pencurian, perampokan, dan tindak kriminalitas lainnya. Kemajuan teknologi elektronika turut membantu dalam pengembangan sistem keamanan yang handal. Salah satunya aplikasi sistem keamanan untuk pengamanan kendaraan bermotor.

Penelitian ini mengambil topik tentang alat pendeteksi maling menggunakan sensor passive infrared atau PIR dan sensor getar berbasis Arduino. Pada alat ini dilengkapi sensor passive infrared yang berfungsi sebagai pendeteksi adanya pancaran gelombang inframerah yang dikeluarkan oleh tubuh manusia dan sensor getar atau $S W-420$ yang berfungsi menangkap getaran dari luar dan mengubahnya menjadi besaran listrik kemudian akan diproses oleh mikrokontroller arduino. Pada alat ini juga menggunakan led sebagai indikator, buzzer sebagai alarm peringatan dan lcd sebagai penampil teks notifikasi keadaan.

Cara kerja sistem ini bekerja dengan 2 sensor, passive infrared akan mendeteksi adanya keberadaan orang atau tidak pada ruangan yang diberi sistem keamanan untuk memerintahkan agar alarm berbunyi dan sensor getar atau $S W-420$ yang berfungsi menangkap getaran dari luar dan mengubahnya menjadi besaran listrik serta memberikan teks notifikasi pada lcd bahwa adanya pergerakan pada sekitar kendaraan.

\section{Rumusan Masalah}

Memuat Berdasarkan permasalahan di atas penulis melakukan perancangan suatu alarm yang dapat mendeteksi keberadaan manusia dan gerakan yang di lakukan pada kendaraan yang terparkir yang mana alarm ini memberikan peringatan atau tanda bahaya ketika kendaraan sedang dalam posisi terparkir.

\section{Tujuan Penelitian}

Merancang suatu alat yang dapat mendeteksi keberadaan manusia dari cakupan sensor melalui inframerah yang di hasilkan tubuh manusia dan getaran dari sentuhan objek ke lingkup sensor getar. Sehingga output atau hasil yang di keluarkan dari alat berbunyi sebagai alarm atau peringatan suatu tanda bahaya seperti maling atau perampok.

\section{Manfaat Penelitian}

1. Diharapkan alarm anti maling ini menjadi alat pengamanan kendraan bermotor yang mudah, praktis dan efektif digunakan.

2. Meningkatnya kreatifitas mahasiswa dalam menemukan hasil karya inovatif yang bermanfaat bagi masyarakat.

3. Salah satu bentuk pengembangan pada sensor PIR(Passive Infrared Receiver) dan sensor getar SW420.

\section{LANDASAN TEORI \\ Kendaraan Bermotor}

Kendaraan bermotor adalah kendaraan yang digerakkan oleh peralatan teknik dan digunakan untuk transportasi darat. Jenis-jenis kendaraan bermotor dapat bermacam-macam, mulai dari mobil, 
bus, sepeda motor, kendaraan off-road, truk ringan, sampai truk berat.(undangundang nomor 28 tahun 2009).

\section{Perancangan}

Perancanganadalah penggambaran, perencanaan dan pembuatan sketsa atau pengaturan dari beberapa elemen yang terpisah ke dalam satu kesatuan yang utuh dan berfungsi sebagai alat yang akan di gunakan untuk suatu manfaat tertentu.(Soetam Rizky, 2011:140)

\section{Alarm Keamanan}

Alarm pengaman atau alarm keamanan adalah alarm elektronik yang dirancang untuk memperingatkan terhadap suatu bahaya tertentu. Sensornya terhubung dengan suatu unit pengendali melalui perkabelan bertegangan rendah atau sinyal berfrekuensi radio sempit yang digunakan untuk berinteraksi dengan piranti respons.(Feri Djuandi, 2011)

\section{Sensor PIR}

Sensor PIR dapat di definisikan sebagai berikut : Sensor PIR adalah sebuah sensor yang biasa di gunakan untuk mendeteksi pergerakan. Pergerakan ini dapat di deteksi dengan mengecek logika high pada pin output. Logika high tersebut dapat di baca oleh mikrokontoller. Perangkat ini berisi filter khusus yang di sebut lensa Fresnel yang memfokuskan lensa inframerah ke elemen.(Wicaksono, Hidayat,2017:161).

\section{Sensor Getar}

Sensor getar dapat di artikan sebagai berikut : Sensor getar merupakan sebuah alat yang mampu merubah besaran fisik seperti gaya, kecepatan perputaran dan penerangan menjadi besaran listrik yang sebanding disebut dengan sensor. Pada sistem keamanan ini digunakan sensor yang sederhana yaitu sensor getar yang berbanding terbalik dari system kerja speaker. Jika speaker biasa listrik dirubah menjadi getaran pada membran speaker, maka saat digunakan sebagai sensor, membran digunakan sebagai penangkap getaran dari luar dan mengubahnya menjadi besaran listrik. (Purnamasari,wijaya,2017:59).

\section{METODE PENELITIAN}

Metode yang penulis gunakan dalam penelitian ini ada dua metode yaitu metode pengumpulan data dan analisis data. Dalam pengumpulan data penulis menggunakan beberapa metode yaitu :

\section{Studi Literatur}

Dalam penyusunan Skripsi ini, penulis mempelajari banyak dari jurnal dan buku yang relevan, yang di dapat melalui internet dan perpustakaan AMIK dan STIKOM Tunas Bangsa yang berkaitan dengan Arduino dan Alarm keamanan.

\section{Studi Lapangan}

Dalam memperoleh data yang sebenarnya penulis melakukan observasi dan wawancara langsung ke petugas parkir RS. Vita Insani sehingga data yang di peroleh valid atau sebenarnya.

\section{Analisis Data.}

Dalam perancangan alarm anti maling berbasis arduino uno sangat diperlukan data atau teknik analisis data, didalam analisis data, peneliti menggunakan teknik analisis deskriptif yang penyajian datanya dalam bentuk tabel yang terdiri dari perangkat keras (Hardware) dan perangkat lunak (Software) dapat dilihat sebagai berikut : 


\section{Perangkat Keras (Hardware)}

Dapat dilihat instrumen dan komponen elektronik dalam pembuatan alarm anti maling berbasis arduino uno seperti pada tabel 3.1 dibawah ini :

Tabel 1. Perangkat Keras Yang Digunakan

\begin{tabular}{|c|c|}
\hline No & $\begin{array}{l}\text { Perangkat Keras Yang } \\
\text { Digunakan }\end{array}$ \\
\hline 1 & Adaptor 5V DC \\
\hline 2 & Arduino Uno Atmega328 \\
\hline 3 & Breadboard \\
\hline 4 & Sensor PIR HC-SR501 \\
\hline 5 & Sensor Getaran SW420 \\
\hline 6 & LCD 16x2 I2C \\
\hline 7 & Kabel Jumper \\
\hline
\end{tabular}

\section{Perangkat Lunak (Software)}

Perancangan perangkat Lunak adalah langkah pembuatan sebuah program yang sesuai dengan algoritma untuk menjalankan sistem alat, dapat dilihat pada tabel dibawah ini adalah Perangkat Lunak (software) yang digunakan.

Tabel 2. Perangkat Lunak Yang

Digunakan

\begin{tabular}{|c|c|}
\hline No & $\begin{array}{c}\text { Perangkat Lunak Yang } \\
\text { Digunakan }\end{array}$ \\
\hline 1 & Software Arduino IDE \\
\hline 2 & Fritzing \\
\hline
\end{tabular}

\section{Kontribusi Penelitian}

Dengan adanya alarm anti maling berbasis arduino uno ini diharapkan dapat mengurangi dan mencegah tindak kejahatan seperti perampokan atau pencurian, dimana sebelumnya tidak tersedianya alat keamanan atau alat pengaman dari pabrikan kendaraan bermotor.

\section{ANALISIS DAN PERANCANGAN}

\section{Analisis Perancangan}

Pada Penelitian ini yaitu dengan menggunakan sensor PIR yang mendeteksi gelombang inframerah dari suatu objek (manusia) yang kemudian di terima sensor akan memberi informasi kepada microkontroler arduino uno untuk di proses dan menghasilkan bunyi berupa peringatan dari buzzer, dan pesan tentang adanya objek yang terdeteksi ke LCD $16 \mathrm{X} 2$ tersebut.

\section{Algoritma Sistem}

Algoritma Sistem adalah suatu urutan dari beberapa langkah yang logis guna menyelesaikan masalah, dengan bertujuan untuk memindahkan proses perancangan ke dalam bentuk yang sesuai berupa alat yang siap untuk di gunakan. Adapun urutan dari Algoritma Sistem adalah :

1. Menentukan alat dan bahan

2. Desain Sistem

3. Merancang alat

4. Ujicoba alat

5. Validasi

\section{Perancangan Penelitian}

Adapun Perancangan Penelitian Penulis dapat dilihat pada gambar flowchart berikut :

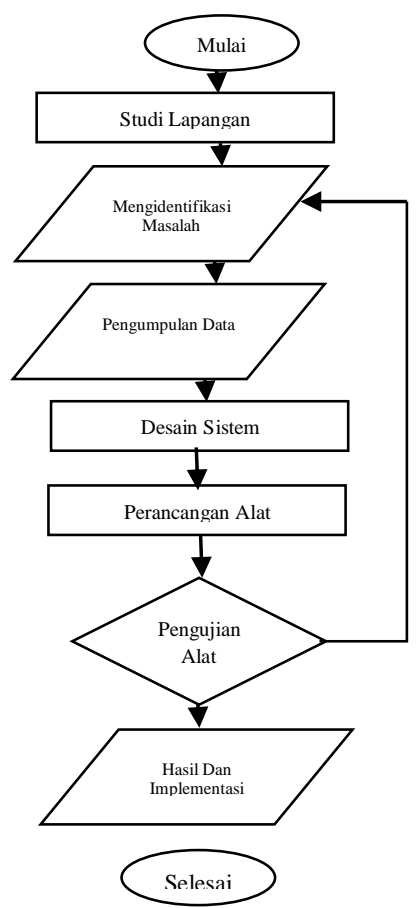

Gambar 1. Flowchart Penelitian 
Penjelasan dari Flowchart Penelitian adalah sebagai berikut :

1. Melakukan Studi lapangan dengan mendatangi langsung lokasi yang bersangkutan.

2. Mengindentifikasi masalah yang sering terjadi di lokasi atau tempat tersebut yaitu dalam menjaga keamanan kendaraan bermotor di posisi parkir.

3. Mendesain sistem alat yang akan di buat.

4. Pembuatan/ Perancangan alat.

5. Melakukan pengujian alat dengan menyesuaikan kondisi sekitar sensor dengan alat yang dibuat.

6. Menghasilkan alat yang dirancang dan Mengimplementasikan alat yang dibuat agar dapat digunakan pada lokasi atau tempat tersebut.

\section{Sistem Kerja Alat}

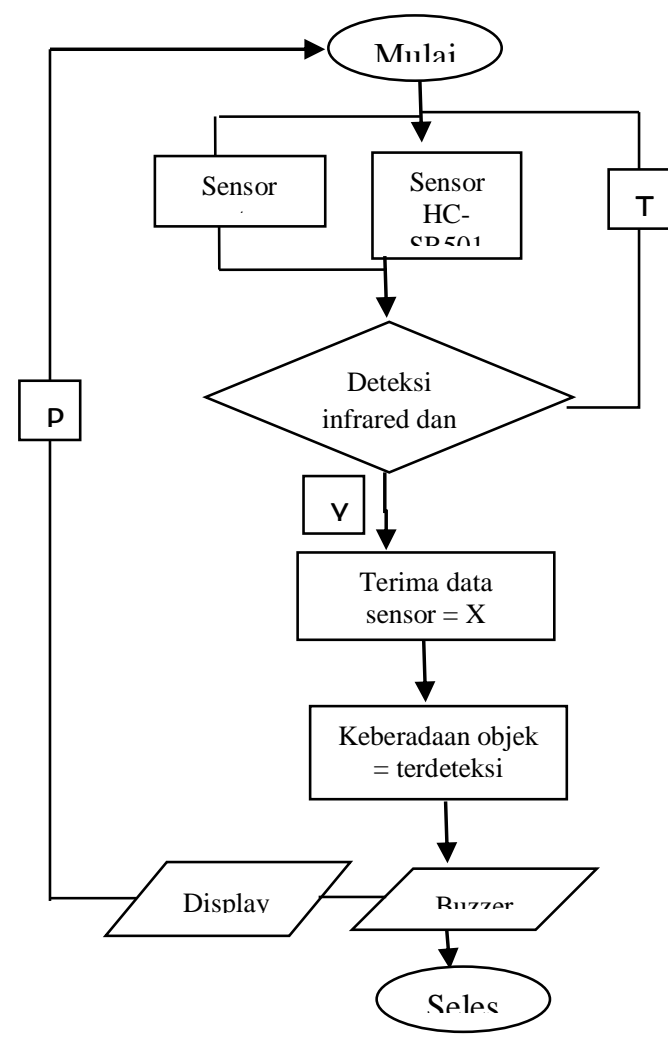

Gambar 2. Flowchart Sistem Kerja Alarm Antimaling Arduino Uno
Penjelasan dari Flowchart Sistem kerja alat adalah sebagai berikut :

1. Sensor getar SW420 dan sensor HCSR501 dalam posisi aktif dan siap untuk mendeteksi objek.

2. Objek terdeteksi dari inframerah dan getaran yang di hasilkan objek, jika tidak terdeteksi (T) maka akan kembali ke langkah awal.

3. Data sensor di terima mikrokontroler dan diproses sebagai keberadaan objek yang terdeteksi.

4. Hasil keluaran/output dari data sensor yang terdeteksi di salurkan ke Display dan Buzzer.

5. Hasil keluaran ini akan terus di ulang (P) dari langkah awal sensor bekerja.

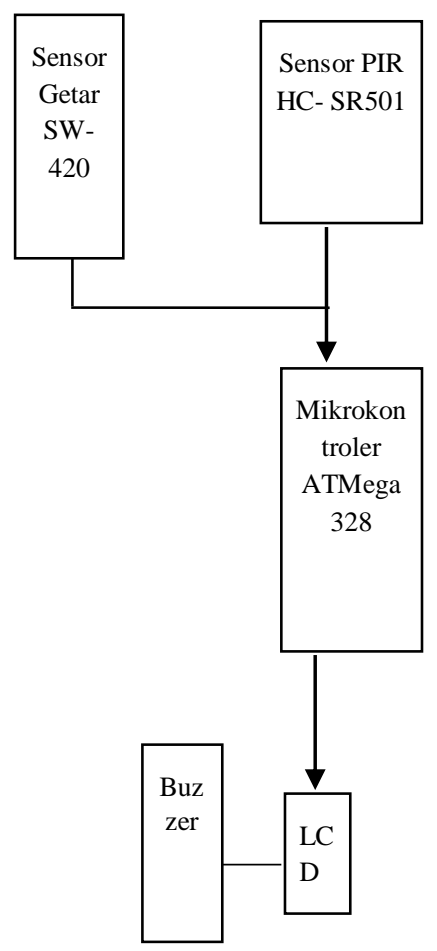

Gambar 3. Diagram Blok Alarm anti Sistem Blok maling

Blok diagram alarm anti maling berbasis arduino dapat dilihat pada gambar berikut. 
Dari gambar diatas, rancang bangun alarm anti maling terdiri tiga bagian yaitu piranti masukan, mikrokontroler dan piranti keluaran. Pada piranti masukan terdapat sensor yang merupakan sumber perintah bagi mikrokontroler tersebut. Adapun jenis sensor yang di pakai yaitu sensor PIR HC-SR501 dan sensor getar $S W-420$ sedangkan pada piranti keluaran adalah LCD 16X2 untuk menampilkan hasil sensor, buzzer untuk menghasilkan bunyi peringatan dari adanya objek yang di deteksi.

\section{Perancangan Sistem Mekanik}

Alarm anti maling berbasis aurduino ini memiliki 2 sensor yang di gunakan yang di hubungkan ke arduino yaitu, sensor PIR dan sensor getar SW-420, rangkaian alur kerja alat ditunjukkan pada gambar 3.4 berikut.

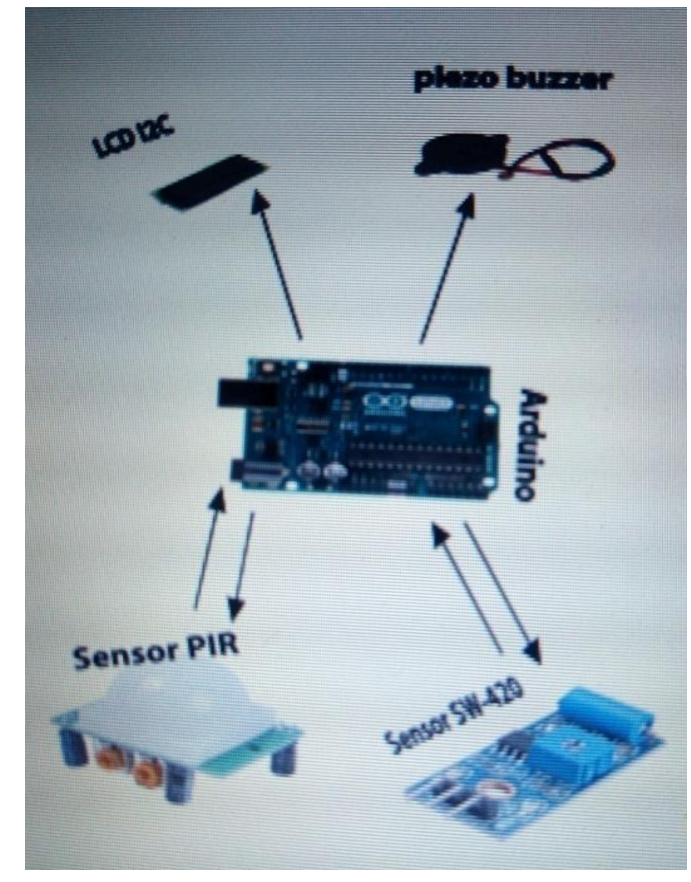

Gambar 4. Rangkaian alur kerja alarm antimaling pada kendaraan bermotor (Sumber: Data Pribadi)
Rangkaian keseluruhan dari alarm anti maling pada kendaraan bermotor ini dapat dibagi menjadi 3 bagian utama yaitu bagian minimum sistem mikrokontroler, bagian input dan bagian output. Bagian minimum sistem mikrokontroler merupakan bagian dimana input dari sensor PIR dan sensor SW420 akan diproses sesuai program yang digunakan kemudian diteruskan kebagian output. Bagian input terdiri dari 2 buah sensor, sensor PIR HC-SR501 yang digunakan sebagai pendeteksi gelombang inframerah dari objek dan sensor getar SW420 untuk mendeteksi getaran yang di hasilkan dari tekanan objek berupa sentuhan. Sedangkan bagian outputnya berupa LCD 16x2 untuk menampilkan keberadaan objek yang di deteksi oleh sensor, buzzer untuk menghasilkan bunyi sebagai alarm peringatan.

\section{IMPLEMENTASI DAN PEMBAHASAN}

Alat yang sudah dirancang selanjutnya akan diteruskan ketahap perakitan dan pengujian. Yang mana alat akan di rakit berdasarkan dengan bentuk rancangan yang sudah di gambarkan, berdasarkan rancangan panjang dan lebar papan prototype alarm adalah $37 \mathrm{~cm} \mathrm{X}$ $23.5 \mathrm{~cm}$ yang dimana sensor $P I R$ berada di kiri dan sensor getar SW420 berada di kanan papan yang mendeteksi adanya objek, kemudian mengirim gelombang inframerah dan getar ke sensor lalu di proses pada arduino sehingga mendapatkan hasil yang akan di tampilkan pada lcd. Dan hasil akhir alat yang telah dibuat dapat dilihat pada gambar berikut.

Rangkaian Keseluruhan Sistem 


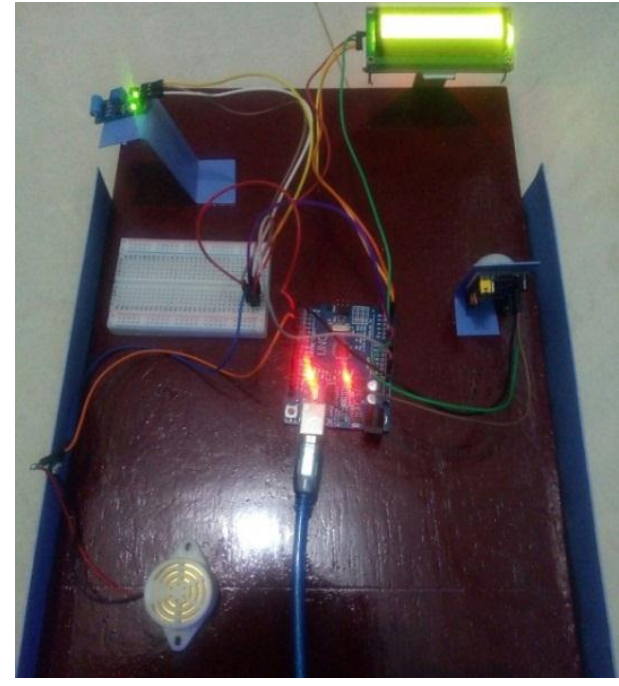

Gambar 5. Hasil Rancangan Alarm antimaling pada Kendaraan ( Sumber: Data Pribadi )

\section{Rancangan Arduino Uno}

Sebelum di uraikan cara prosedur kerja sistem arduino uno, terlebih dahulu penulis akan menguraikan hasil rancangan dalam pembuatan alarm antimaling pada kendaraan bermotor berbasis arduino. Proses perakitan alat ini adalah perpaduan antara microcontroler Arduino Uno (ATMEGA328) dengan Sensor PIR $\mathrm{HC}$ SR501, Sensor getar SW420, LCD, buzzer dan beberapa komponen pendukung seperti Kabel Jumper, I2C, papan board dan lainnya. Skema rangkaian pada alat yang telah dirakit dapat dilihat pada gambar berikut

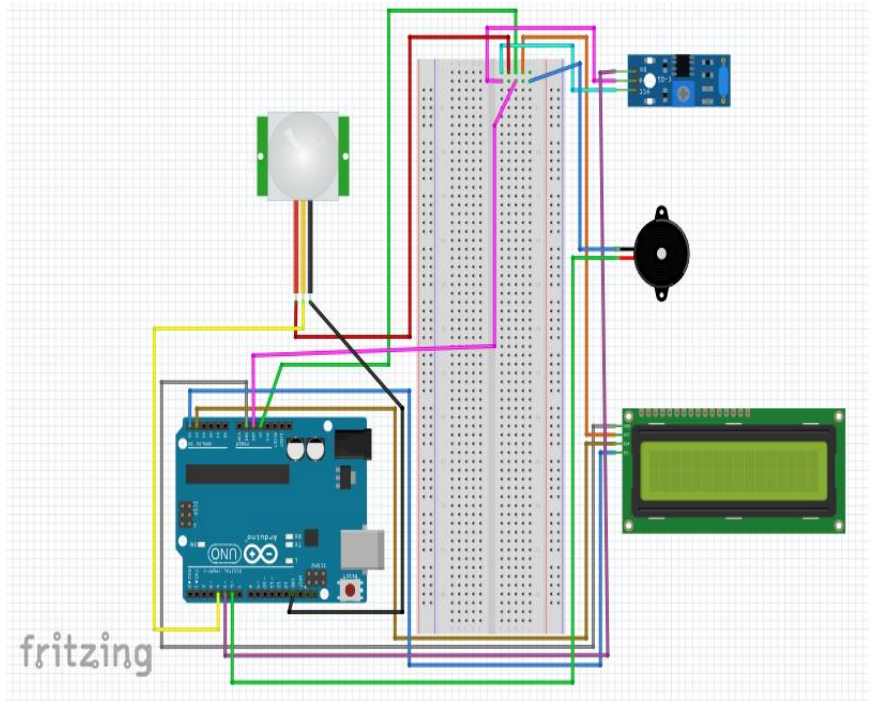

Gambar 6. Rangkaian Arduino ( Sumber: fritzing )

Dari skema rangkaian yang terlihat pada gambar diatas kemudian dirangkai dengan instalasi dan pemasangan Arduino dan modul lainnya dengan mengkoneksikan pin di setiap modul ke pin yang terdapat pada Arduino Uno tersebut. Pin yang saling terkoneksi diatas dapat kita lihat sebagai berikut :

1. Penyesuaian pin pada rangkaian Arduino dengan yang ada di code program yang dibuat.

2. Kaki SCL I2c LCD koneksikan pada pin A5 Arduino

3. Kaki SDA I2c LCD koneksikan pada pin A4 Arduino

4. Kaki VCC I2c LCD koneksikan pada pin 5V Arduino

5. Kaki GND I2c LCD koneksikan pada pin GND (Ground) Arduino

6. Kaki VCC Sensor PIR koneksikan pada pin 5V Arduino

7. Kaki GND Sensor PIR koneksikan pada pin GND Arduino

8. Kaki OUT Sensor PIR koneksikan pada pin 4 Arduino

9. Kaki Echo Sensor Ultrasonic koneksikan pada pin 3 Arduino 
10. Kaki GND Sensor getar koneksikan ke kabel jumper board pada pin GND Arduino

11. Kaki VCC Sensor getar koneksikan ke kabel jumper board pada pin $5 \mathrm{~V}$ Arduino

12. Kaki DO Sensor getar koneksikan ke kabel jumper board pada pin 5 Arduino

13. Kaki pin 2 (merah) buzzer koneksikan pada pin 6 Arduino

14. Kaki pin 1 (hitam) buzzer koneksikan ke kabel jumper board pada pin GND Arduino

Setelah melakukan pengkoneksian pin modul kedalam Arduino proses selanjutnya adalah melakukan pemberian perintah kepada Arduino dengan berupa code program menggunakan bahasa $\mathrm{C}$ dengan software Arduino IDE. Sehingga rangkaian yang telah dibuat bisa berjalan sesuai dengan yang penulis harapkan sebagaimana mestinya.

\section{Masukan (Input)}

Perancangan perangkat lunak pada program mikrokontroler arduino ini menggunakan software arduino IDE yang berbasis bahasa $\mathrm{C}++$ yang telah dipermudah melalui library. Arduino menggunakan Software Processing yang digunakan untuk menulis program kedalam arduino.

Sebelum menggunakan alarm antimaling pada kendaraan bermotor, arduino harus terlebih dahulu dimasukkan berupa kode-kode agar arduino bekerja sesuai dengan ketentuan yang ingin dibuat. Untuk memasukkan program kedalam sebuah mikrokontroler arduino, dibutuhkan Driver USB, IDE Arduino 1.8.9, Ardunio Uno Board dan kabel printer usb type A to B agar program yang dibuat dapat berjalan di dalam mikrokontroler. Dengan membuat program sebagai berikut, dapat dilihat pada gambar 4.3. Adapun source code program dapat dilihat pada halaman lampiran.

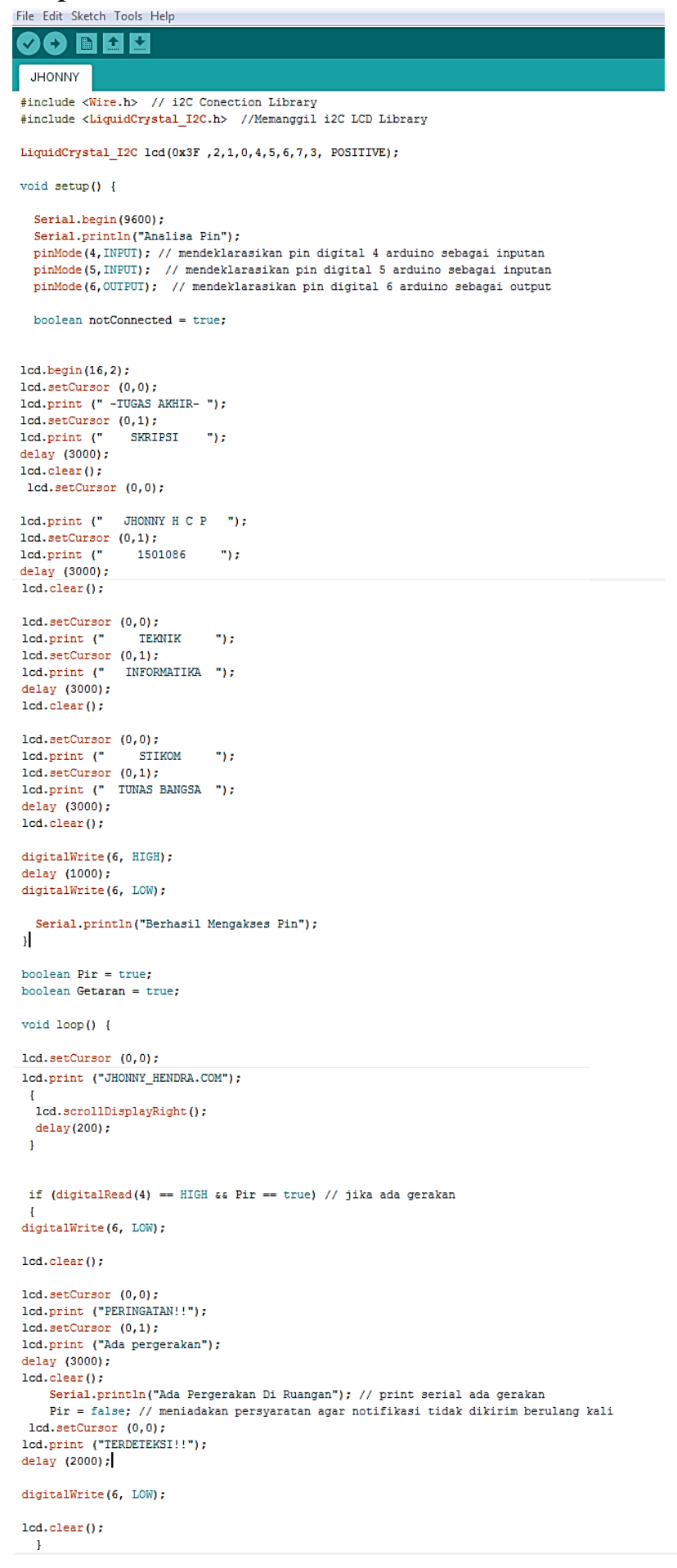




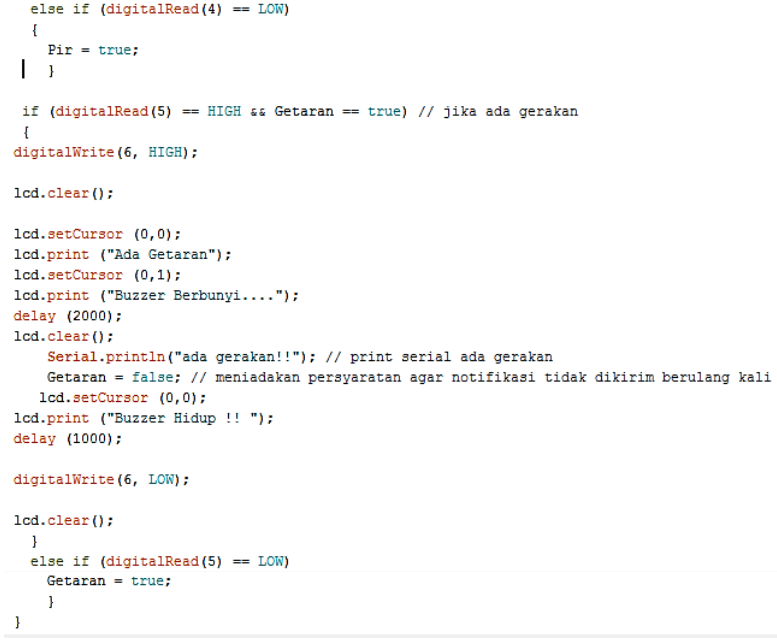

Gambar 7. Coding Arduino ( Sumber: Arduino IDE )

Sensor PIR HC-SR501 dan sensor getar SW420 adalah hardware yang memberikan input perintah kepada arduino agar memproses data yang akan dikirimkan sebagai output.

Berikut penampakan sensor sebagai input terlihat pada gambar berikut.
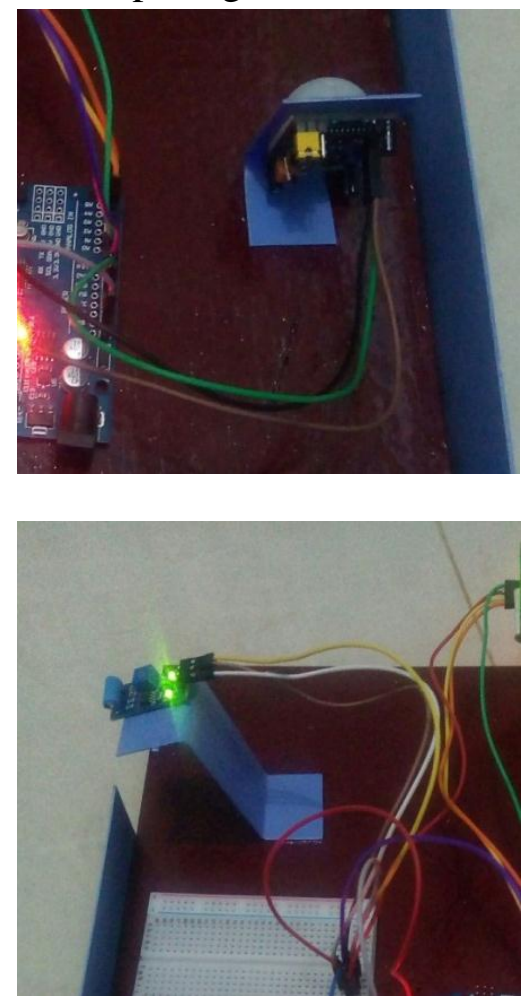

Gambar 8.Sensor HC-SR501 dan Sensor Getar SW420
( Sumber: Data Pribadi)

Pemrosesan (Proses)

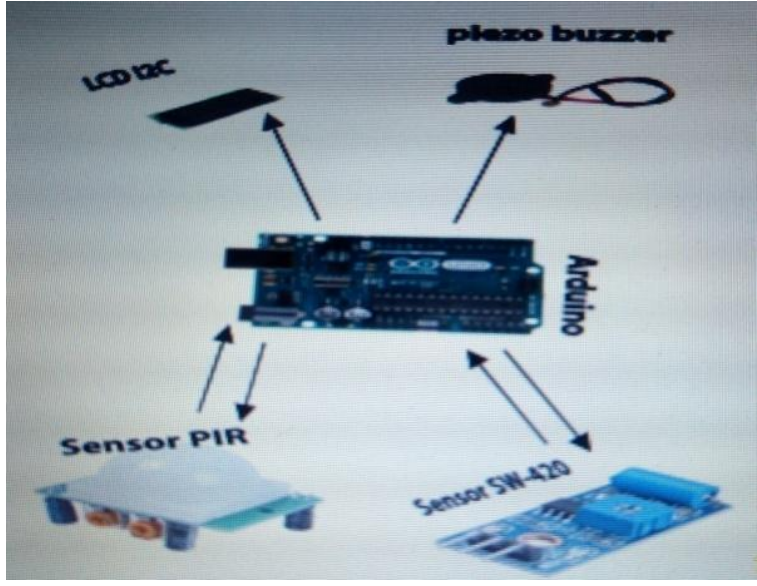

Gambar 9.Bentuk Proses Kerja Alat ( Sumber: Data Pribadi )

Data yang diterima dari sensor $P I R$ HC-SR501 dan sensor getar SW420 kemudian akan diproses oleh mikrokontroler Arduino uno dan dari hasil pemrosesan oleh Arduino akan ditampilkan kedalam LCD.

\section{Keluaran (Output)}

Tampilan hasil dari deteksi sensor akan terlihat pada layar LCD yang dapat dilihat pada gambar 4.6 berikut.
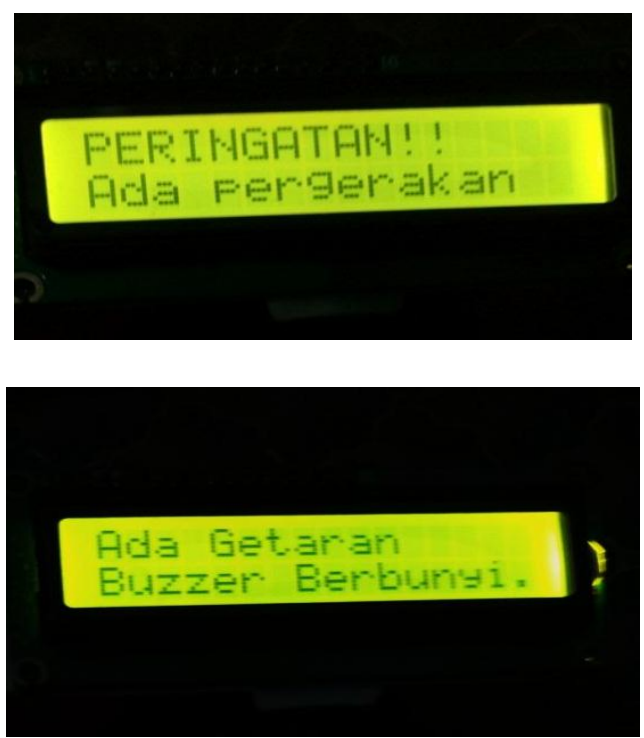
Gambar 10. Hasil Pendeteksian Pada tampilan LCD

( Sumber: Data Pribadi )

\section{KESIMPULAN}

Kesimpulan yang didapat adalah dengan menggunakan Arduino Uno ATMega328 yang dihubungkan dengan Sensor PIR HC-SR501 membangun sebuah interface antara sistem dengan subsistem lainnya yang membentuk suatu integrasi sistem yang membentuk satu kesatuan. Pada alarm antimaling berbasis arduino setelah dilakukan uji alat maka dapat disimpulkan bahwa Alat ini berhasil dijalankan sesuai dengan kondisi yang terdeteksi oleh sensor HC-SR501, dengan memberi tampilan pada LCD.

\section{Saran}

Alarm antimaling pada kendaraan ini diharapkan dapat dikembangkan dengan menambahkan komponen elektronik yang dapat menghubungkan pemilik dengan kendaraannya secara otomatis dengan sistem kendali mesin kendaraan yang dapat di starter dan di matikan hanya oleh pemilik kendaraan. Atau menambahkan modul lokasi ke kendaraan jika yang menggunakan kendaraan bukan pemiliknya.

\section{DAFTAR PUSTAKA}

Rahman, M. N. Yusfi, M. (2015) 'Rancang Bangun Sistem Alarm Gempa Bumi berbasis mikrokontroler avr atmega 16 menggunakan sensor piezoelektrik', Jurnal Fisika Unand, Volume 4 nomor 4 oktober 2015 hlm 350-356.

Mochtiarsa, Y. Supriadi, B. (2016) 'Rancangan Kendali Lampu Menggunakan Mikrokontroller atmega328 Berbasis Sensor Getar', Jurnal Informatika SIMANTIK, Vol.1, No.1, September 2016 hlm 40-44.
Purnamasari, W. Wijaya, R. (2017) 'Sistem Keamanan Rumah Menggunakan Sensor Getaran Dengan Output Suara Berbasis $P C$, Jurnal Mantik Penusa, Vol.21 No.1, juni 2017:59-63.

Kurnia, D. Hidayatulloh, R, F. (2016) 'Integrasi Teknik Pendeteksian Obyek Mengunakan Sensor PIR Dengan Kontrol Pergerakan sliding camera pada sistem keamanan bengkel', Jurnal Simetris, Vol. 7, No.2, Hal. 587-595, november 2016.

Saleh, M. Haryanti, M. (2017) 'Rancang Bangun Sistem Keamanan Rumah Menggunakan Relay', Jurnal Teknologi elektro,Universitas mercu Buana, Volume 8 nomor 3 September 2017 hlm 181-185.

Wicaksono, M.F \& Hidayat. 2017 'Mudah Belajar Mikrokontroler Arduino' Bandung : Informatika Bandung.

Hidayat, M. R. Christiono, Sapudin, B. S. (2018) 'Perancangan Sistem Keamanan Rumah Berbasis IOT Dengan Nodemcu esp8266 Mengunakan Sensor PIR hcsr501 dan Sensor Smoke Detector', Jurnal Kilat, Volume 7 nomor 2 september 2018 hlm 139-148

Rahmatullah, G. M. Ayat, M. Suteddy, M. (2018) 'Sistem Antimaling Untuk Rumah Tinggal Menggunakan IOT Bluemix', Jurnal Teknologi Rekayasa, Volume 3 nomor 1 juni 2018 hlm 55-68

Setiawan, E. (2015) 'Aplikasi Alarm Antimaling Berbasis Mikrokontroler At Mega 8535', Jurnal SISFOKOM, Volume 04, nomor 02 september $2015 \mathrm{hlm}$ 28-34

Rodiansyah, N. Utama, H. S. Setianingsih, E. (2019) 'Perancangan Sistem Keamanan Parkir Sepeda Berbasis Radio Frequency Indentification', Jurnal TESLA, Volume 21 nomor 1 maret 2019 hlm 192-204 